\section{(อ)} OPEN ACCESS

\title{
Riociguat in patients with early diffuse cutaneous systemic sclerosis (RISE-SSc): randomised, double- blind, placebo-controlled multicentre trial
}

\author{
Dinesh Khanna (D) , 1 Yannick Allanore, ${ }^{2}$ Christopher P Denton (D) , \\ Masataka Kuwana (D) , ${ }^{4}$ Marco Matucci-Cerinic, ${ }^{5}$ Janet E Pope (D) , ${ }^{6}$ Tatsuya Atsumi, \\ Radim Bečvárr, ${ }^{8}$ László Czirják, ${ }^{9}$ Eric Hachulla, ${ }^{10}$ Tomonori Ishii, $^{11}$ Osamu Ishikawa, ${ }^{12}$ \\ Sindhu R Johnson (D) , ${ }^{13}$ Ellen De Langhe, ${ }^{14}$ Chiara Stagnaro, ${ }^{15}$ Valeria Riccieri, ${ }^{16}$ \\ Elena Schiopu, ${ }^{17}$ Richard M Silver (D) , ${ }^{18}$ Vanessa Smith, ${ }^{19}$ Virginia Steen, ${ }^{20}$ \\ Wendy Stevens, ${ }^{21}$ Gabriella Szücs, $^{22}$ Marie-Elise Truchetet, ${ }^{23}$ Melanie Wosnitza, $^{24}$ \\ Kaisa Laapas, ${ }^{25}$ Janethe de Oliveira Pena, ${ }^{26}$ Zhen Yao, $^{27}$ Frank Kramer, ${ }^{24}$ \\ Oliver Distler (1D ${ }^{28}$
}

\begin{abstract}
Handling editor Josef $S$ Smolen

- Additional material is published online only. To view please visit the journal online (http://dx.doi.org/10.1136/ annrheumdis-2019-216823)
\end{abstract}

For numbered affiliations see end of article.

\section{Correspondence to} Dr Dinesh Khanna, Division of Rheumatology, University of Michigan, Ann Arbor, Ml 48109, USA; khannad@med.umich.edu and Dr Oliver Distler,

Department of Rheumatology, University Hospital Zurich, 8091 Zurich, Switzerland:

oliver.distler@usz.ch

For 'Presented at statement' see end of article.

Received 13 December 2019 Revised 19 February 2020 Accepted 9 March 2020

\section{ABSTRACT}

Objectives Riociguat is approved for pulmonary arterial hypertension and has antiproliferative, anti-inflammatory and antifibrotic effects in animal models of tissue fibrosis. We evaluated the efficacy and safety of riociguat in patients with early diffuse cutaneous systemic sclerosis (dcSSc) at high risk of skin fibrosis progression.

Methods In this randomised, double-blind, placebocontrolled, phase IIb trial, adults with dcSSc of $<18$ months' duration and a modified Rodnan skin score (mRSS) 10-22 units received riociguat $0.5 \mathrm{mg}$ to $2.5 \mathrm{mg}$ orally three times daily $(n=60)$ or placebo $(n=61)$. The primary endpoint was change in mRSS from baseline to week 52.

Results At week 52, change from baseline in mRSS units was $-2.09 \pm 5.66(n=57)$ with riociguat and $-0.77 \pm 8.24(n=52)$ with placebo (difference of least squares means $-2.34(95 \% \mathrm{Cl}-4.99$ to $0.30 ; p=0.08)$ ). In patients with interstitial lung disease, forced vital capacity declined by $2.7 \%$ with riociguat and $7.6 \%$ with placebo. At week 14, average Raynaud's condition score had improved $\geq 50 \%$ in $19(41.3 \%) / 46$ patients with riociguat and $13(26.0 \%) / 50$ patients with placebo. Safety assessments showed no new signals with riociguat and no treatment-related deaths.

Conclusions Riociguat did not significantly benefit mRSS versus placebo at the predefined $p<0.05$. Secondary and exploratory analyses showed potential efficacy signals that should be tested in further trials. Riociguat was well tolerated.

\section{Key messages}

What is already known about this subject?

- There is a need for new therapies for patients with diffuse cutaneous systemic sclerosis (dcSSc).

- The soluble guanylate cyclase stimulator riociguat has antiproliferative, antiinflammatory and antifibrotic effects in vitro and in animal models of tissue fibrosis and has been shown to increase digital blood flow in patients with Raynaud's phenomenon.

What does this study add?

- The Rlociguat Safety and Efficacy in patients with diffuse cutaneous Systemic Sclerosis study failed to meet its primary endpoint of change in modified Rodnan skin score after 52 weeks at $p=0.08$. However, some secondary and exploratory endpoints showed potential efficacy signals that should be investigated in further trials. Riociguat was well tolerated, with no unexpected safety signals.

How might this impact on clinical practice or future developments?

- Although the primary endpoint was not significant, this phase Ilb study provides important information that can inform future study design and gave preliminary findings that could be explored in future trials in patients with dcSSc.
Check for updates

(C) Author(s) (or their employer(s)) 2020. Re-use permitted under CC BY. Published by BMJ.

\footnotetext{
To cite: Khanna $D$,

Allanore Y, Denton CP,

et al. Ann Rheum Dis

2020;79:618-625.
}

\section{INTRODUCTION}

Systemic sclerosis (SSc) is an autoimmune connective tissue disease characterised by fibrosis, inflammation and microvascular injury. ${ }^{1-3}$ Systemic organ manifestations include pulmonary arterial hypertension (PAH), interstitial lung disease (ILD), Raynaud's phenomenon (RP) and digital ulcers (DU). ${ }^{34}$ To date, nintedanib is the only approved therapy for the treatment of SSc-ILD. ${ }^{5}$ Thus there is a significant unmet need, particularly in diffuse cutaneous SSc $(\mathrm{dcSSc})$. $^{3}$

The soluble guanylate cyclase (sGC) stimulator riociguat increases intracellular cyclic guanosine monophosphate (cGMP). ${ }^{7}$ cGMP activates protein kinases $G$, which are important in the regulation of vascular tone and remodelling. ${ }^{8}$ Riociguat was approved for treatment of PAH following the phase 
III Pulmonary Arterial Hypertension Soluble Guanylate CyclaseStimulator Trial 1 (PATENT-1) study, which included a subgroup with PAH-SSc, in which riociguat prevented the decline in $6 \mathrm{~min}$ walking distance seen with placebo. ${ }^{9}$ In a single-dose pilot study, riociguat increased digital blood flow in patients with RP. ${ }^{10}$ Riociguat has demonstrated antiproliferative, anti-inflammatory and antifibrotic effects mediated by attenuation of transforming growth factor beta-1 signalling in animal models and in vitro studies. $^{7811-14} \mathrm{sGC}$ stimulators prevented and treated fibrosis in models of SSc. ${ }^{1215}$

We hypothesised that riociguat may benefit tissue fibrosis in dcSSc. The RIociguat Safety and Efficacy in patients with diffuse cutaneous Systemic Sclerosis (RISE-SSc) trial compared riociguat with placebo in patients with early dcSSc. ${ }^{16-18}$

\section{METHODS}

\section{Design overview}

RISE-SSc (clinicaltrials.gov identifier: NCT02283762 ${ }^{19}$ ) was a randomised, double-blind, placebo-controlled, parallel-group, phase IIb, international, multicentre study, consisting of a screening phase ( $\leq 2$ weeks), a 52-week, double-blind, main treatment phase and a long-term extension (see online supplementary figure S1 and supplementary file 2). All patients provided written informed consent. Each site's institutional review board or ethics committee approved the protocol. The study was performed in accordance with the Declaration of Helsinki and Good Clinical Practice.

\section{Study participants}

Investigators enrolled patients $\geq 18$ years old, fulfilling American College of Rheumatology/European League Against Rheumatism (ACR/EULAR) classification criteria for $\mathrm{SSc},{ }^{20}$ with dcSSc according to LeRoy and Medsger. ${ }^{21}$ Based on European Scleroderma Trials and Research Group (EUSTAR) cohort observations, ${ }^{16-18}$ entry criteria specified disease duration $\leq 18$ months (defined as time from first non-RP manifestation) and modified Rodnan skin score (mRSS) 10-22 units to enrich the study with patients at risk of skin fibrosis progression. Other inclusion criteria were per cent predicted forced vital capacity (FVC\%) $\geq 45 \%$ and haemoglobin-corrected per cent predicted diffusing capacity of the lung for carbon monoxide $\left(\mathrm{DL}_{\mathrm{CO}}\right)$ $\geq 40 \%$ at screening. Patients receiving concomitant nitrates, nitric oxide donors, phosphodiesterase inhibitors or recent SSc therapies were excluded (see online supplementary file 1, p1-3).

\section{Randomisation and intervention}

Patients were randomised 1:1 to riociguat or matching placebo, individually adjusted every 2 weeks from $0.5 \mathrm{mg}$ to $2.5 \mathrm{mg}$ orally three times daily over 10 weeks and continued throughout the treatment phase. From week 26, rescue therapy was permitted at investigator discretion (see online supplementary file 1, p4). Physical examination, disease status and demographics were obtained at day 0 . Disease status was re-evaluated at weeks 12 , 26 and 52, with additional assessments of mRSS and pulmonary function at week 39. Raynaud's condition score was assessed by a patient diary completed daily for seven consecutive days before the first treatment dose and at week 14. Safety assessments included laboratory assessments at screening, on day 0 , and at weeks 2, 4, 6, 8, 10, 26, 39 and 52, and evaluation of vital signs, adverse events (AEs) and serious adverse events (SAEs) coded by Medical Directory for Regulatory Activities preferred terms, DU net burden and prior and concomitant therapy at every visit.

\section{Outcomes and follow-up}

The primary endpoint was the change in mRSS from baseline to week 52. To prevent interobserver variability, the same physician, experienced in skin scoring, scored the same patient throughout the study. Skin fibrosis was also analysed by prespecified exploratory analyses of mRSS progression (increase by $>5$ units and $\geq 25 \%$ from baseline) and regression (decrease by $>5$ units and $\geq 25 \%$ from baseline). This definition was based on analyses suggesting that a reduction in mRSS of 3.2-5.3 units or $15 \%-25 \%$ from baseline is considered a minimally clinically important difference. ${ }^{22} 23$ In addition, descriptive analysis in prespecified patient subgroups was performed (see online supplementary file 1, p4). Secondary endpoints were tested hierarchically in the order: American College of Rheumatology Composite Response Index for Systemic Sclerosis (ACR CRISS) at week $52^{24}$ (see online supplementary file 1, p5-6), Health Assessment Questionnaire Disability Index, patient's global assessment, physician's global assessment and change in $\mathrm{FVC} \%$. An independent, blinded Adjudication Committee reviewed clinical outcomes potentially representing systemic organ manifestations of dcSSc (see online supplementary file 1, p6), and all causes of death.

FVC $\%$ and $\mathrm{DL}_{\mathrm{CO}} \%$ were assessed overall and (post hoc) in patients with ILD according to medical history and restrictive lung disease (FVC\% 50\%-75\% at baseline).

Effects on RP at week 14 versus day 0 and net digital ulcer burden were prespecified exploratory analyses. For details of other prespecified exploratory analyses and post hoc assessments see online supplementary file $1, \mathrm{p} 6$.

\section{Statistical analysis}

Assuming a standard deviation (SD) of 8 mRSS units, ${ }^{25} 80 \%$ power, a two-sided significance level of 5\% and 1:1 randomisation, 128 patients would be required to detect a placeboadjusted difference of 4 units for intent-to-treat analysis of mRSS. Endpoints were analysed using mixed model repeated measures, with baseline mRSS as a covariate; treatment arm, region and study visit, the interaction effect between study visit and treatment arm as fixed effects and patient-specific random effects (see online supplementary file 3 ). The primary endpoint was also analysed by analysis of covariance with baseline mRSS as a covariate, and treatment arm and region as main effects. Endpoints present or not were estimated using Mantel-Haenszel weights. Analyses were performed on all patients randomised and treated with study medication using SAS V.9.2 software (SAS Institute Inc, Cary, North Carolina, USA). Since the primary endpoint was not met, all other $\mathrm{p}$ values are nominal, are only shown for predefined but not post hoc analyses, cannot be considered statistically significant and are presented for information only.

\section{Patient involvement}

Patients were not directly involved in the design, recruitment or conduct of the study.

\section{RESULTS}

\section{Study population}

In total, 121 patients were randomised (riociguat, $n=60$; placebo, $\mathrm{n}=61$ ). The study was completed according to the protocol. Five patients in each group received $\geq 1$ new rescue therapy after week 26. Study discontinuation occurred in 18 (30.0\%) riociguat-treated patients and $15(24.6 \%)$ placebo-treated patients (figure 1). At week 52, $34(80.9 \%) / 42$ riociguat-treated 


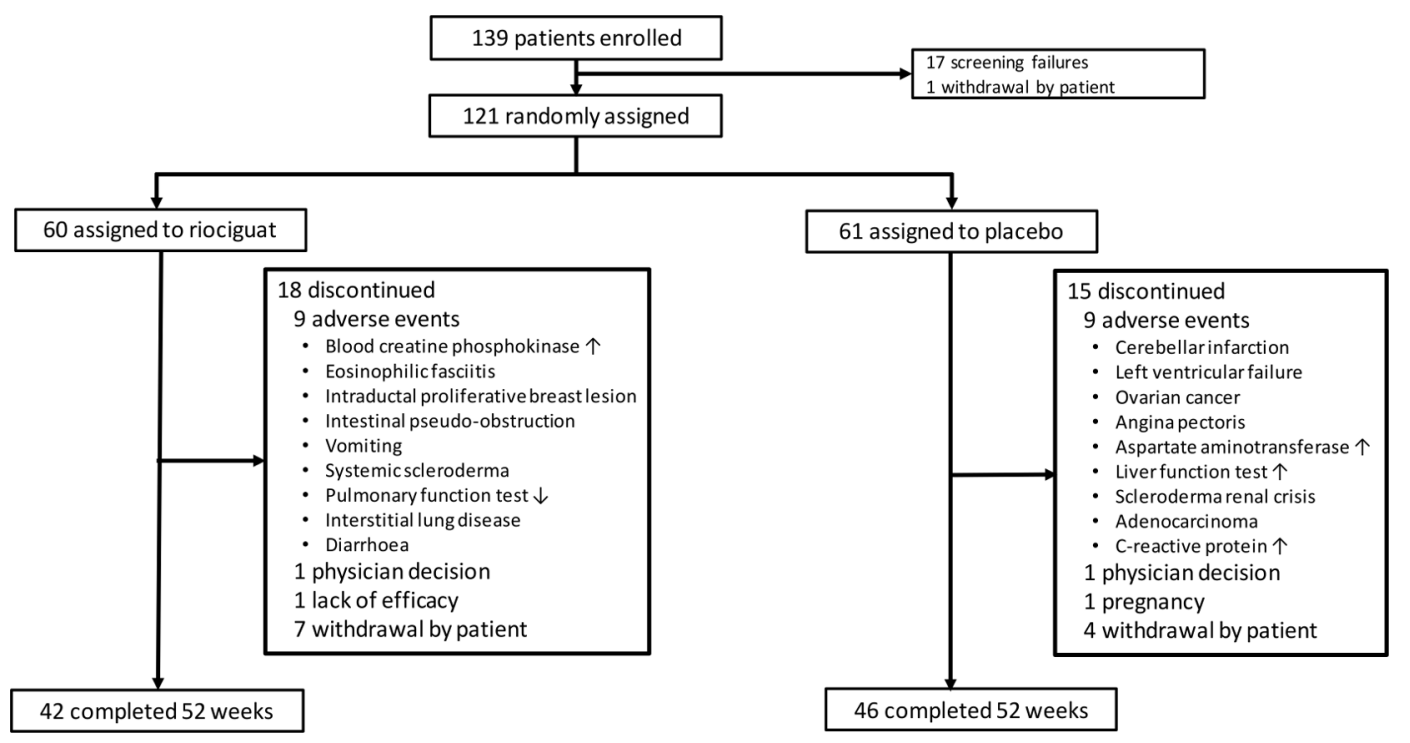

Figure 1 Patient disposition.

patients were receiving riociguat 2 or $2.5 \mathrm{mg}$ three times daily. Patients generally had early dcSSc, with mean mRSS 17 and mean disease duration 8.6 months. Baseline characteristics were generally well balanced across groups (table 1).

\section{Skin fibrosis}

The primary endpoint was not met at the predefined $\mathrm{p}<0.05$. At week 52, mean mRSS was 14.63 (SD 6.56) with riociguat

\begin{tabular}{|c|c|c|c|}
\hline Characteristics & $\begin{array}{l}\text { Overall } \\
(n=121)\end{array}$ & $\begin{array}{l}\text { Riociguat } \\
(n=60)\end{array}$ & $\begin{array}{l}\text { Placebo } \\
(n=61)\end{array}$ \\
\hline Mean age (SD), years & $50.7(12.2)$ & $51.9(11.5)$ & $49.5(12.9)$ \\
\hline Female, $n(\%)$ & $92(76.0)$ & $47(78.3)$ & $45(73.8)$ \\
\hline White, $n(\%)$ & $89(73.6)$ & $43(71.7)$ & $46(75.4)$ \\
\hline Black, n (\%) & $5(4.1)$ & $2(3.3)$ & $3(4.9)$ \\
\hline Asian, $\mathrm{n}(\%)$ & $24(19.8)$ & $12(20.0)$ & $12(19.7)$ \\
\hline Native Hawaiian or other Pacific Islander, $\mathrm{n}(\%)$ & $1(0.8)$ & $1(1.7)$ & 0 \\
\hline Not reported, $\mathrm{n}(\%)$ & $2(1.7)$ & $2(3.3)$ & 0 \\
\hline $\begin{array}{l}\text { Mean disease duration (SD), months (from first } \\
\text { non-RP manifestation) }\end{array}$ & $9.0(6.4)$ & $9.5(7.0)$ & $8.6(5.8)$ \\
\hline Mean mRSS (SD), units & $16.8(3.7)$ & $16.9(3.4)$ & $16.7(4.1)$ \\
\hline Mean $\%$ predicted FVC (SD), \% & $92.8(17.8)$ & $90.7(18.5)$ & $94.8(17.0)$ \\
\hline Mean \% predicted $\mathrm{DL}_{\mathrm{co}}$ (Hb corr.) (SD), \% & $76.4(18.5)$ & $76.0(19.9)$ & $76.8(17.2)$ \\
\hline Swollen joint count $\geq 1, n(\%)$ & $38(31.4)$ & $23(38.3)$ & $15(24.6)$ \\
\hline Mean swollen joint count (SD), $n$ & $2.0(4.7)$ & $3.0(6.1)$ & $1.1(2.5)$ \\
\hline Tender joint count $\geq 1, \mathrm{n}(\%)$ & $51(42.1)$ & $30(50.0)$ & $21(34.4)$ \\
\hline Mean tender joint count (SD), $n$ & $3.0(6.2)$ & $3.9(7.3)$ & $2.1(4.8)$ \\
\hline Digital ulcer count $\geq 1, n$ (\%) & $15(12.4)$ & $9(15.0)$ & $6(9.8)$ \\
\hline Mean digital ulcer count (SD), $n$ & $0.3(1.1)$ & $0.3(0.7)$ & $0.4(1.4)$ \\
\hline $\begin{array}{l}\text { Mean digital ulcer count in patients with ulcers } \\
\text { (SD), } \mathrm{n}\end{array}$ & $2.5(2.3)$ & $1.7(1.0)$ & $3.7(3.2)$ \\
\hline Tendon friction rubs $\geq 1, \mathrm{n}(\%)$ & $35(28.9)$ & $15(25.0)$ & $20(32.8)$ \\
\hline Mean tendon friction rubs (SD), $\mathrm{n}$ & $3.1(2.2)$ & $2.4(1.1)$ & $3.6(2.7)$ \\
\hline ILD by medical history, $\mathrm{n}(\%)$ & $25(20.7)$ & $12(20.0)$ & $13(21.3)$ \\
\hline Mean HAQ-DI (SD), units & $0.79(0.68)$ & $0.89(0.67)$ & $0.69(0.69)$ \\
\hline Anti-RNA polymerase III positive, n (\%) & $26(21.5)$ & $10(16.7)$ & $16(26.2)$ \\
\hline Anti-SCI-70 (anti-topoisomerase I) positive, n (\%) & $49(40.5)$ & $26(43.3)$ & $23(37.7)$ \\
\hline Anti-centromere B positive, $\mathrm{n}(\%)$ & $10(8.3)$ & $4(6.7)$ & $6(9.8)$ \\
\hline
\end{tabular}

versus 15.73 (SD 10.48) with placebo: difference of least squares (LS) means -2.34 (standard error (SE) 1.33); 95\% confidence interval (CI) -4.99 to 0.30 ; relative difference $-14 \% ; \mathrm{p}=0.0815$. At week 52, the mean change from baseline in mRSS was -2.09 (SD 5.66) with riociguat and -0.77 (SD 8.24) with placebo (figure 2A). Progression of mRSS (increase by $>5$ units and $\geq 25 \%$ from baseline) was observed in $11(18.6 \%) / 59$ patients with riociguat and $22(36.7 \%) / 60$ patients with placebo (MantelHaenszel estimate of difference: $-17.99 \%$ (95\% CI $-33.57 \%$ to $-2.40 \%$; nominal $\mathrm{p}=0.0237$ ); figure $2 \mathrm{~B}$ ). Regression rates (decrease by $>5$ units and $\geq 25 \%$ from baseline) in the riociguat and placebo groups were 27 (45.7\%)/59 and $18(30.0 \%) / 60$, respectively (Mantel-Haenszel estimate of difference: $15.29 \%$ (95\% CI $-1.98 \%$ to $32.57 \%$; nominal $\mathrm{p}=0.0827)$ ).

On subgroup analyses, the change in mRSS with riociguat versus placebo showed a nominal $\mathrm{p}$ value $<0.05$ for mRSS 17-22, anti-RNA polymerase III positive/SCl-70 negative, baseline FVC $50 \%-75 \%$ and high-sensitivity C-reactive protein $>3.0 \mathrm{mg} / \mathrm{L}$ (see online supplementary figure S2).

\section{Secondary endpoints}

ACR CRISS as a measure of improvement did not show significant differences in this trial designed for prevention of worsening. Eighteen per cent of patients in each group had a CRISS improvement probability score $\geq 0.60$ (estimate of difference: $0.20 \%$ (95\% CI $-13.68 \%$ to $14.09 \%$; nominal $\mathrm{p}=0.977)$ ). However, in step 1 of the CRISS analysis, 1 (1.7\%) patient in the riociguat group versus $4(6.6 \%)$ in the placebo group met the definition for SSc-related organ involvement. Other secondary endpoints are shown in table 2.

\section{Lung function}

Overall, the change in FVC\% between baseline and week 52 was $-2.38 \%$ (SD 7.52) with riociguat and $-2.95 \%$ (SD 9.73) with placebo (difference of LS means -0.20 (SE 1.61); 95\% CI -3.40 to 3.00 ; nominal $\mathrm{p}=0.901$; figure $3 \mathrm{~A}$ ). Two patients in each group developed new ILD. At baseline, 12 (20.0\%) patients receiving riociguat and $13(21.3 \%)$ patients with placebo had SSc-ILD by medical history, and 11 (18.3\%) and 7 (11.5\%), respectively, had baseline FVC\% 50\%-75\%. Baseline characteristics by lung fibrosis diagnosis are shown in online supplementary 


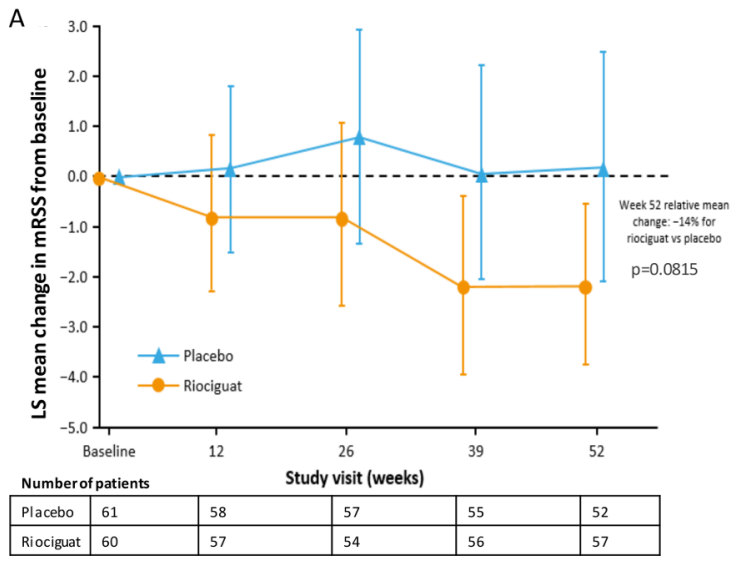

B

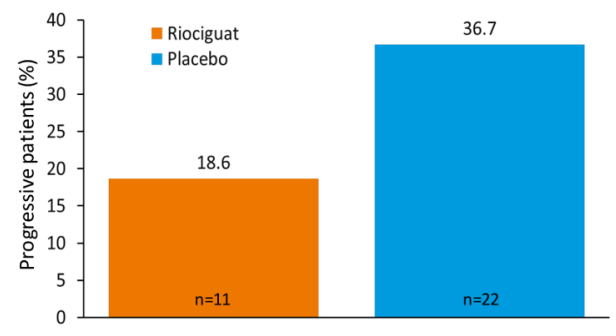

Figure 2 (A) Change from baseline in mRSS during the study. Mixed model with repeated measurement was applied with baseline value, treatment group, region, visit and treatment by visit interaction as fixed effects, and subject as a random effect. Vertical lines represent $95 \% \mathrm{Cl}$ for change. (B) Proportion of patients with mRSS progression (increase in mRSS by $>5$ units and $\geq 25 \%$ from baseline: prespecified analysis). Treatment comparison (riociguat -placebo): estimate $-17.99 \%, 95 \% \mathrm{Cl}-33.57$ to -2.40 . Mantel-Haenszel estimate of difference: nominal $\mathrm{p}=0.0237$. Cl, confidence interval; LS, least squares; mRSS, modified Rodnan skin score.

table S1. Depending on the diagnosis, the mean change in FVC\% from baseline to week 52 was -7.6 to $-8.7 \%$ with placebo and +0.7 to $-2.7 \%$ with riociguat (figure $3 \mathrm{~B}$ ).

$\mathrm{DL}_{\mathrm{CO}} \%$ decreased by $-2.31 \%$ (SD 10.08) with riociguat and $-4.09 \%$ (SD 12.19) with placebo (difference of LS means 2.01 (SE 2.14); 95\% CI -2.24 to 6.25 ; nominal $p=0.3502$ ). In patients with ILD by medical history the changes in $\mathrm{DL}_{\mathrm{CO}} \%$ were -4.55 (SD 8.12) with riociguat $(\mathrm{n}=11)$ and $-7.63(\mathrm{SD} 13.37)$ with placebo $(\mathrm{n}=12)$. In those with baseline $\mathrm{FVC} \%$ 50\%-75\%, $\mathrm{DL}_{\mathrm{CO}} \%$ increased by 2.26 (SD 15.16) with riociguat $(\mathrm{n}=8)$ and fell by -7.32 (SD 17.24) with placebo $(n=5)$.

\section{Raynaud's phenomenon and digital ulcers}

At baseline, 9 (15.0\%) patients had DUs in the riociguat group versus $6(9.8 \%)$ in the placebo group. New DUs were reported in $2(3.3 \%)$ patients in the riociguat group and $6(9.8 \%)$ in the placebo group at week 14, and in $5(8.3 \%)$ patients and $12(19.7 \%)$ patients, respectively, at week 52 . There were 4 and 26 new DUs with riociguat and placebo, respectively, at week 14; and 12 and 72 new DUs, respectively, at week 52 (see online supplementary figure S3). Concomitant medication with an indication for DU was used by 7 (11.7\%) patients receiving riociguat and $10(16.4 \%)$ patients with placebo. Changes from baseline to week 14 in Raynaud's attack duration, frequency and symptoms favoured riociguat but nominally did not differ significantly between riociguat and placebo (see online supplementary table S2). The average Raynaud's condition score improved by $\geq 50 \%$ in $19(41.3 \%) / 46$ patients with riociguat and in $13(26.0 \%) / 50$ patients with placebo. At week 52, reductions in net DU burden were -0.09 (SD 0.50)

Table 2 Difference between riociguat group and placebo group in change from baseline to week 52 in secondary endpoints

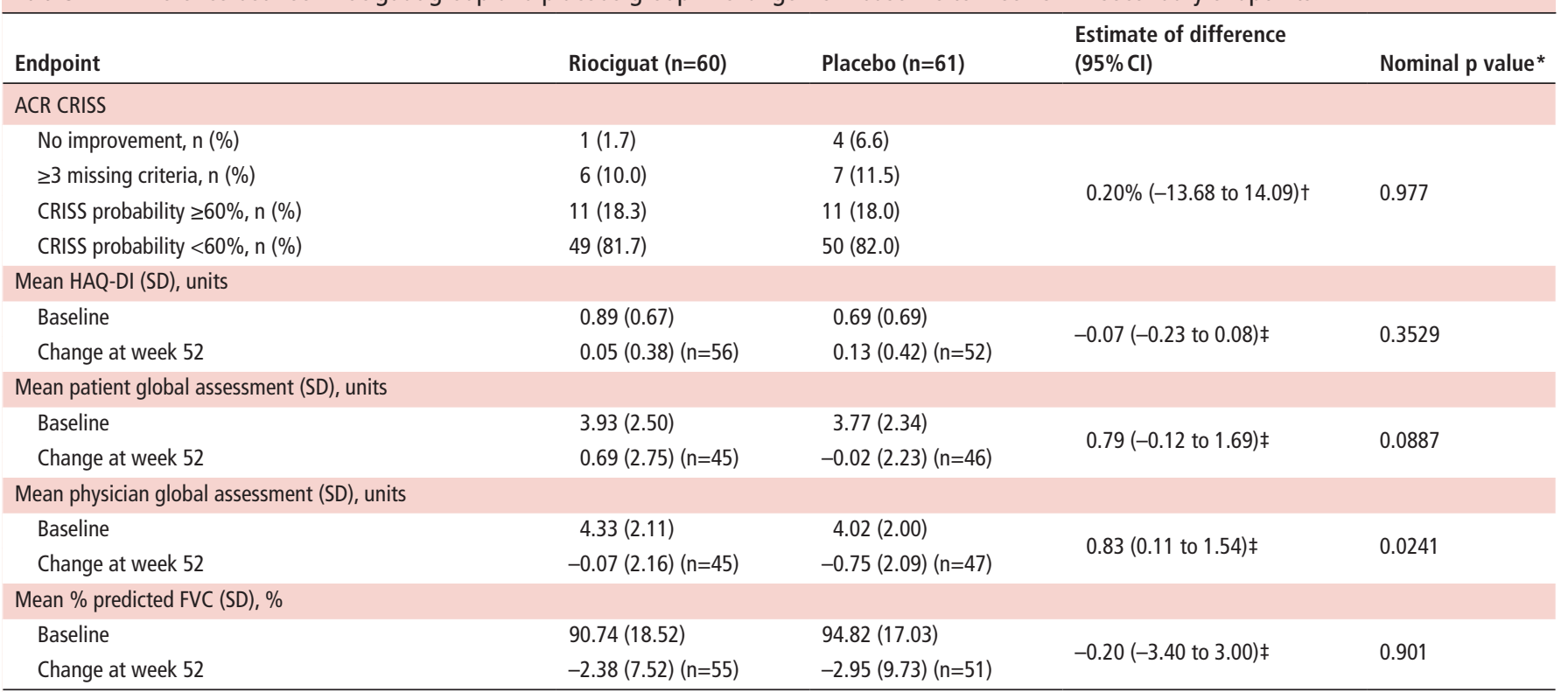

${ }^{*}$ Since the primary endpoint was not met, all other $p$ values cannot be considered statistically significant and are presented for information only.

tMantel-Haenszel estimate.

¥Mixed model repeated measures applied with baseline value, treatment group, region, visit and treatment by visit interaction as fixed effects, and subject as a random effect. ACR, American College of Rheumatology; Cl, confidence interval; CRISS, Composite Response Index for Systemic Sclerosis; FVC, forced vital capacity; HAQ-DI, Health Assessment Questionnaire Disability Index. 


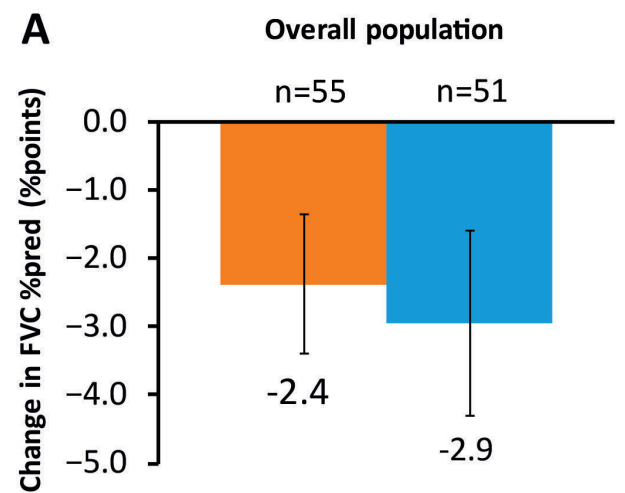

Difference of LS means at Week 52: $-0.2(95 \% \mathrm{Cl}-3.40$ to 3.00$)$ nominal $\mathrm{p}=0.901$
Placebo

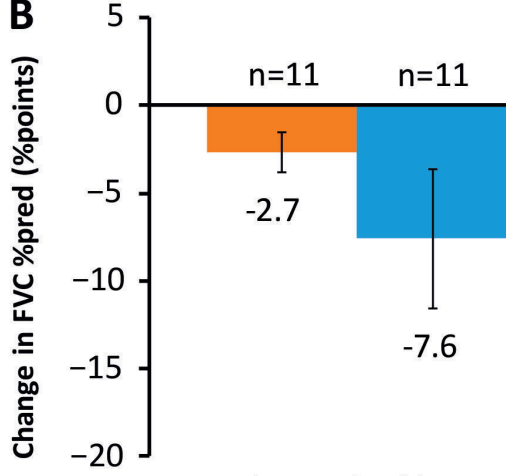

ILD by medical history

$\begin{array}{lllll}\text { Improvement by }>3 \%, \mathrm{n}(\%) & 1(9.1) & 2(18.2) & 2(25.0) & 0 \\ \text { Worsening by }>3 \%, \mathrm{n}(\%) & 5(45.5) & 5(45.5) & 2(25.0) & 2(50.0)\end{array}$

Restrictive lung disease Figure 3 (A) Change in FVC\% from baseline to week 52 in overall population. (B) Change in FVC\% from baseline to week 52 in patients with lung
fibrosis at baseline by diagnostic subgroups (post hoc). Data points are mean (SE). Numbers close to axes are numbers of patients with data at week 52. Cl, confidence interval; FVC, forced vital capacity; ILD, interstitial lung disease; LS, least squares; SE, standard error.

and -0.08 (SD 1.47) with riociguat and placebo, respectively (difference of LS means -0.11 (SE 0.14); 95\% CI -0.38 to 0.17 ; nominal $\mathrm{p}=0.4444)$. No case of critical digital ischaemia occurred in either group.

\section{Other endpoints}

Findings from prespecified exploratory analyses and post hoc assessments are provided in online supplementary file 1, p12-19.

\section{Adverse events}

Overall, 58 (96.7\%) patients in the riociguat group and 55 (90.2\%) in the placebo group experienced an AE (see online supplementary table S8). Most AEs in the riociguat group were mild to moderate, and most were gastrointestinal events (eg, gastro-oesophageal reflux disease, diarrhoea or nausea) or nervous system disorders (eg, dizziness, headache). Symptomatic hypotension was reported in $7(11.7 \%)$ patients with riociguat and $6(9.8 \%)$ patients with placebo. SAEs were reported in 9 $(15.0 \%)$ patients in the riociguat group and $15(24.6 \%)$ in the placebo group (table 3 ). Eleven patients in each group had AEs resulting in discontinuation of study drug (see online supplementary table S9). No events of serious haemoptysis were reported. One patient in the riociguat group died from myocardial infarction 117 days after the last administration of riociguat and one patient in the placebo group died from left ventricular failure 157 days after the last administration of placebo. Neither death was considered related to study drug.

Of those with ILD by medical history, AEs were reported in 10 $(83.3 \%) / 12$ patients with riociguat and 12 (92.3\%)/13 patients with placebo. AEs reported more frequently with riociguat than with placebo were predominantly dizziness and gastrointestinal events (see online supplementary table S10). The incidence of respiratory, thoracic and mediastinal AEs was similar with riociguat (4 patients; $33.3 \%$ ) and placebo (4 patients; 30.8\%). SAEs were reported in $1(8.3 \%) / 12$ and $3(23.1 \%) / 13$ patients, respectively. Safety in patients with baseline FVC\% 50\%-75\% showed no overall excess of AEs with riociguat (see online supplementary table S11).

\section{DISCUSSION}

RISE-SSc investigated the effects of riociguat on disease progression in patients with early dcSSc. mRSS was selected as the primary endpoint as it correlates with biopsy measures of skin thickness and reflects disease prognosis and visceral involvement. ${ }^{126} \mathrm{mRSS}$ does, however, have challenging and unpredictable changes over the disease course and attempts to enrich trial populations with patients likely to progress have not been successful. Nevertheless, it is a validated surrogate marker of disease progression ${ }^{27}$ and is accepted by authorities as an endpoint for skin fibrosis. ${ }^{22}$ RISE-SSc was the first trial in SSc with the EUSTAR inclusion criteria designed to enrich the population with patients likely to show progression of skin fibrosis. Between baseline and week 52, $36.7 \%$ of placebo-treated patients showed skin fibrosis progression, which is much higher than in similar trials, ${ }^{25} 28-30$ showing that our enrichment strategy was successful. This is consistent with other evidence that patients with baseline mRSS 15-22 and early disease showed higher progression rates than unselected cohorts. ${ }^{171831}$

There are several potential reasons why the primary endpoint was not met in this study. First, RISE-SSc was designed to detect a placebo-adjusted change of mRSS between riociguat and placebo with $80 \%$ power. For the low baseline mRSS expected in this study, a 4-unit change would represent a change of $23 \%$. The between-groups difference was 2.3 , which was less than expected. This low treatment effect was probably the main reason why the primary endpoint was not met. In addition, the higher than expected numbers of skin fibrosis regressors ${ }^{18}$ and stable patients reduced the sensitivity of RISE-SSc to detect a significant change of mRSS. This is consistent with previous trials, in which mRSS improvements were observed in the majority of patients receiving placebo. ${ }^{32} 33$ Other possible explanations include the very large variation in mRSS scores during the study.

As expected, the combined secondary endpoint did not favour riociguat because the ACR CRISS evaluates disease improvement, whereas RISE-SSc was designed to detect prevention of progression. ACR CRISS is not expected to be positive in such a trial design. ${ }^{24}$ 
Table 3 Serious adverse events

\begin{tabular}{|c|c|c|}
\hline \multicolumn{3}{|l|}{ Patients reporting event, $\mathrm{n}(\%)$} \\
\hline Event & Riociguat $(n=60)$ & Placebo $(n=61)$ \\
\hline Any SAE & $9(15.0)$ & $15(24.6)$ \\
\hline Any study drug-related SAE & 0 & $2(3.3)$ \\
\hline Discontinuation of study drug due to SAE & $2(3.3)$ & $7(11.5)$ \\
\hline Angina pectoris & $1(1.7)$ & $1(1.6)$ \\
\hline Atrial fibrillation & $1(1.7)$ & 0 \\
\hline Abdominal pain & $1(1.7)$ & 0 \\
\hline Intestinal pseudo-obstruction & $1(1.7)$ & 0 \\
\hline Inflammation & $1(1.7)$ & 0 \\
\hline Lung infection & $1(1.7)$ & 0 \\
\hline Pneumonia & $1(1.7)$ & $2(3.3)$ \\
\hline $\mathrm{RP}$ & $1(1.7)$ & $1(1.6)$ \\
\hline Musculoskeletal discomfort & $1(1.7)$ & 0 \\
\hline Pain in extremity & $1(1.7)$ & 0 \\
\hline Dyspnoea & $1(1.7)$ & 0 \\
\hline Intraductal proliferative breast lesion & $1(1.7)$ & 0 \\
\hline Pericarditis & 0 & $2(3.3)$ \\
\hline Left ventricular failure & 0 & $1(1.6)$ \\
\hline Ventricular tachycardia & 0 & $1(1.6)$ \\
\hline Gastric haemorrhage & 0 & $1(1.6)$ \\
\hline Gastro-oesophageal reflux disease & 0 & $1(1.6)$ \\
\hline Nausea & 0 & $1(1.6)$ \\
\hline Vomiting & 0 & $1(1.6)$ \\
\hline Infected skin ulcer & 0 & $1(1.6)$ \\
\hline Anaemia & 0 & $1(1.6)$ \\
\hline Exposure during pregnancy & 0 & $1(1.6)$ \\
\hline Osteolysis & 0 & $1(1.6)$ \\
\hline Scleroderma & 0 & $1(1.6)$ \\
\hline Acute myeloid leukaemia & 0 & $1(1.6)$ \\
\hline Gastric adenocarcinoma & 0 & $1(1.6)$ \\
\hline Ovarian cancer & 0 & $1(1.6)$ \\
\hline Cerebellar infarction & 0 & $1(1.6)$ \\
\hline Syncope & 0 & $1(1.6)$ \\
\hline Scleroderma renal crisis & 0 & $1(1.6)$ \\
\hline Acute pulmonary oedema & 0 & $1(1.6)$ \\
\hline Skin ulcer & 0 & $1(1.6)$ \\
\hline Surgical/medical prophylaxis & 0 & $1(1.6)$ \\
\hline
\end{tabular}

MedDRA preferred terms are shown.

MedDRA, Medical Directory for Regulatory Activities; RP, Raynaud's phenomenon; $\mathrm{SAE}$, serious adverse event.

Some measures of mRSS, lung function in patients with evidence for pre-existing ILD and the prevention of new DU and RP symptoms suggest potential signals for efficacy. It is important to note that the descriptive analyses of predefined secondary and exploratory endpoints should not be interpreted as efficacy of riociguat, but as a potential signal that can be investigated in further studies.

AEs reported more frequently with riociguat than placebo were mainly gastrointestinal events, dizziness or peripheral oedema. These events are consistent with the effects of riociguat, such as relaxation of smooth muscle cells in the vasculature (often associated with blood pressure decrease) or the gastrointestinal tract and did not increase the incidence of withdrawal due to AEs. SAEs were less common with riociguat than with placebo, no riociguat-treated patient experienced an SAE considered related to study treatment, and fewer discontinued study medication because of an SAE with riociguat than with placebo. Riociguat was, therefore, well tolerated in early dcSSc, particularly when compared with traditional immunosuppressive agents. ${ }^{34} 35$ Tolerability was also good in patients with ILD, which is important given the increased rates of death and SAEs with riociguat in a study in patients with pulmonary hypertension associated with idiopathic interstitial pneumonia. ${ }^{36}$

Discontinuation rates $(\approx 30 \%$ with riociguat and $\approx 25 \%$ with placebo) were higher in RISE-SSc than with active treatment in recent trials of abatacept $(23 \%)^{37}$ or tocilizumab $(9 \%)^{38}$ in SSc. RISE-SSc recruited patients with very early disease (compared with these trials, which recruited patients with $\leq 36$ and $\leq 60$ months from onset of SSc, respectively). The early discontinuation may be related to the expectation of worsening of SSc in early disease (based on natural history), where AEs may lead the investigator to withdraw the patient (see online supplementary table S9), especially in a placebo-controlled trial. Indeed, another trial with a comparable very early disease population showed a discontinuation rate of $40 \%$ in the active treatment (CAT-192) group. ${ }^{39}$ Another explanation might be anxiety associated with early disease in the participants; however, these are speculations and should be explored in other trials in patients with very early disease. AEs in the riociguat and placebo groups contributed substantially to the discontinuations in the current study.

In conclusion, RISE-SSc failed to meet its primary endpoint and is therefore a negative trial. However, it provides important findings for the identification of patients at high risk of skin fibrosis progression that could inform future studies in patients with dcSSc. In addition, there are potential efficacy signals in early dcSSc and these may be explored further with additional randomised controlled trials.

\section{Author affiliations}

${ }^{1}$ Division of Rheumatology, University of Michigan, Ann Arbor, Michigan, USA ${ }^{2}$ Rheumatology A department, Cochin Hospital, APHP, Paris Descartes University, Paris, France

${ }^{3}$ Division of Medicine, Centre for Rheumatology, University College London, London, UK

${ }^{4}$ Department of Allergy and Rheumatology, Nippon Medical School Graduate School of Medicine, Tokyo, Japan

${ }^{5}$ Department of Experimental and Clinical Medicine, University of Florence, Firenze, Italy

${ }^{6}$ Schulich School of Medicine, Division of Rheumatology, The University of Western

Ontario, London, Ontario, Canada

${ }^{7}$ Department of Rheumatology, Endocrinology and Nephrology, Faculty of Medicine and Graduate School of Medicine, Hokkaido University, Sapporo, Japan

${ }^{8}$ Institute of Rheumatology, Department of Rheumatology, 1st Faculty of Medicine,

Charles University, Prague, Czech Republic

${ }^{9}$ Department of Rheumatology and Immunology, University of Pécs, Pécs, Hungary

${ }^{10}$ Department of Internal Medicine and Clinical Immunology, Claude Huriez Hospital,

Lille University School of Medicine, Lille, France

${ }^{11}$ Clinical Research, Innovation and Education Center, Tohoku University Hospital,

Sendai, Japan

${ }^{12}$ Department of Dermatology, Gunma University Postgraduate School of Medicine,

Maebashi, Japan

${ }^{13}$ Division of Rheumatology, Department of Medicine, Toronto Western Hospital, University Health Network, Mount Sinai Hospital, University of Toronto, Toronto Scleroderma Research Program, Toronto, Ontario, Canada

${ }^{14}$ Laboratory of Tissue Homeostasis and Disease, Skeletal Biology and Engineering Research Center, Department of Development and Regeneration, KU Leuven, Leuven, Belgium

${ }^{15}$ Rheumatology Unit, Department of Clinical and Experimental Medicine, University of Pisa, Pisa, Italy

${ }^{16}$ Department of Clinical Medicine and Therapy, University of Rome La Sapienza, Rome, Italy

${ }^{17}$ Division of Rheumatology, Department of Internal Medicine, Michigan Medicine University Hospitals, Ann Arbor, Michigan, USA

${ }^{18}$ Division of Rheumatology and Immunology, Medical University of South Carolina, Charleston, South Carolina, USA

${ }^{19}$ Department of Rheumatology and Internal Medicine, Ghent University Hospital, Ghent, Belgium 
${ }^{20}$ Division of Rheumatology, Georgetown University Medical Center, Washington, DC, USA

${ }^{21}$ Department of Rheumatology, St. Vincent's Hospital Melbourne, Melbourne, Victoria, Australia

${ }^{22}$ Division of Rheumatology, Department of Internal Medicine, University of Debrecen, Debrecen, Hungary

${ }^{23}$ Department of Rheumatology, CHU Bordeaux, Bordeaux, France

${ }^{24}$ Research \& Development, Bayer AG, Wuppertal, Germany

${ }^{25}$ StatFinn Oy, Espoo, Finland

${ }^{26}$ Bayer HealthCare Pharmaceuticals Inc, Whippany, New Jersey, USA

${ }^{27}$ Bayer Healthcare, Beijing, China

${ }^{28}$ Department of Rheumatology, University Hospital, Zurich, Switzerland

\section{Presented at}

Preliminary results from this study have been presented at scientific congresses as described below. Khanna D, et al. RISE-SSc: a double-blind, randomised study evaluating the efficacy and safety of riociguat for the treatment of patients with diffuse cutaneous systemic sclerosis. European League Against Rheumatism (EULAR) Congress, Madrid, Spain, 14-17 June 2017. Ann Rheumat Dis 2017;76(Suppl. 2): Abstract no. AB0627. Distler O, et al. Riociguat in patients with early diffuse cutaneous systemic sclerosis: a randomized, double-blind, placebo-controlled phase Ilb study (RISE-SSc). Arthritis Rheumatol 2018;70(Suppl. 9): Abstract no. 903. Khanna D, et al. The effects of riociguat on Raynaud's phenomenon and digital ulcers in patients with diffuse systemic sclerosis: results from the phase llb RISE-SSc study. Arthritis Rheumatol 2018;70(Suppl. 10): Abstract no. 1879. Khanna $D$, et al. The effects of riociguat on Raynaud's phenomenon and digital ulcers in patients with diffuse systemic sclerosis: results from the phase IIb RISE-SSc study. European League Against Rheumatism (EULAR) Congress, Madrid, Spain, 12-15 June 2019. Ann Rheumat Dis 2019;78(Suppl. 2): Abstract no. FRI0303. Distler 0, et al. Efficacy and safety of riociguat in patients with early diffuse cutaneous systemic sclerosis and interstitial lung disease (SSc-ILD): results from the phase IIb RISE-SSC study. European League Against Rheumatism (EULAR) Congress, Madrid, Spain, 12-15 June 2019. Ann Rheumat Dis 2019;78(Suppl. 2):167.1-167. Distler O, et al. Efficacy and safety of riociguat in patients with early diffuse cutaneous systemic sclerosis and interstitial lung disease (SSc-ILD): results from the phase IIb RISE-SSC study. Am J Respir Crit Care Med 2019;199:A4086. Hemmrich M, et al. Efficacy and safety of riociguat in patients with early diffuse cutaneous systemic sclerosis: results from the RISE-SSc study, a randomised, double-blind, placebo-controlled phase Ilb study. 9th International Conference on cGMP: Generators, Effectors and Therapeutic Implications, Mainz, Germany, 14-16 June 2019. J Translational Med 2019;17:51-03

Acknowledgements We thank the investigators and patients in the RISE-SSc trial, as well as the Data Monitoring Committee, and the Central Adjudication Committee.

Contributors DK and OD attest to the accuracy and completeness of the reported data, had full access to all data, wrote the report and made the final decision to submit the manuscript for publication. DK, OD, YA, CPD, MK, MMC, TA, RB, LC, EH, TI, OI, SRJ, EDL, MM-C, VR, ES, RMS, VSm, VSt, WS, GS, and MET recruited and monitored patients and collected study data. All authors revised the report and approved the final draft for publication.

Funding The study was jointly funded by Bayer AG and Merck Sharp \& Dohme Corp., a subsidiary of Merck \& Co., Inc., Kenilworth, NJ, USA. Bayer AG designed the study in collaboration with the authors. DK and OD have access to the data. KL worked with Bayer AG as an external statistician. MW analysed and interpreted the results and led post hoc analysis generation. Medical writing services provided by Richard Murphy PhD, of Adelphi Communications Ltd, Macclesfield, UK were funded by Bayer AG, Berlin, Germany in accordance with Good Publication Practice (GPP3) guidelines.

Competing interests DK reports personal fees from Actelion, grants and persona fees from Bayer AG, grants and personal fees from BMS, grants from Pfizer, personal fees from Arena, personal fees from Eclos Sciences, Inc, personal fees from BI, personal fees from Arena, personal fees from CSL Behring, personal fees from GSK, personal fees from Galapagos, personal fees from Genentech/Roche, personal fees from Corbus, personal fees from Cytori, grants from Horizon, outside the submitted work. OD reports other from Actelion, other from Bayer, other from Boehringer Ingelheim, other from Mitsubishi Tanabe, other from AnaMar, other from ChemonAb, other from espeRare Foundation, other from Genentech/Roche, other from GSK, other from Inventiva, other from Italfarmaco, other from iQvia, other from Lilly, other from Medac, other from Medlmmune, other from Pharmacyclics, other from Novartis, other from Pfizer, other from Sanofi, other from Serodapharm, other from UCB, other from Amgen, other from AbbVie, other from Mepha, other from MSD, outside the submitted work. YA reports personal fees from Actelion, personal fees from Bayer $A G$, grants and personal fees from BMS, grants from Inventiva, personal fees from $\mathrm{BI}$, grants from Roche, grants from Sanofi, outside the submitted work. CPD reports personal fees from Actelion, personal fees from Bayer $A G$, grants and personal fees from Inventiva, personal fees from BI, personal fees from Roche-Genentech, personal fees from Sanofi Aventis, grants and personal fees from CSL Behring, grants and personal fees from GlaxoSmithKline, outside the submitted work. MK reports grants and personal fees from Actelion, personal fees from Bayer AG, personal fees from Chugai, personal fees from Bl, personal fees from Reata, personal fees from Corpus, personal fees from CSL Behring, personal fees from GlaxoSmithKline, personal fees from Mochida, personal fees from Pfizer, personal fees from Nippon Shinyaku, outside the submitted work. MMC reports grants and personal fees from Actelion, grants from Chemomab, grants and personal fees from BMS, grants from Pfizer, grants and personal fees from MSD, grants from Sanipedia, personal fees from Janssen, outside the submitted work. JEP reports personal fees from Actelion, personal fees from Bayer AG, personal fees from BMS, personal fees from AbbVie, personal fees from Lilly, personal fees from Roche, personal fees from Sanofi, personal fees from Merck, personal fees from Novartis, personal fees from Pfizer, personal fees from Sandoz, personal fees from UCB, personal fees from Amgen, outside the submitted work. TA reports grants and personal fees from Astellas, grants and personal fees from Takeda, grants and personal fees from Mitsubishi Tanabe, grants and personal fees from Chugai, grants and personal fees from Daiichi-Sankyo, grants from Otuska, grants from Takeda, grants and personal fees from Pfizer, grants from Alexion, grants from Bayer, grants from Eisai, grants from Bristol-Myers Squibb, grants from Asahi Kasei, personal fees from Ono, personal fees from Sanofi, personal fees from Eli Lilly, outside the submitted work. LC reports personal fees from Actelion, personal fees from Bayer $A G$, personal fees from $B I$, personal fees from Roche-Genentech, personal fees from Lilly, personal fees from Medac, personal fees from Novartis, personal fees from Pfizer, outside the submitted work. EH reports grants, personal fees and non-financial support from Actelion, grants, personal fees and non-financial support from Bayer AG, grants, personal fees and non-financial support from GlaxoSmithKline, grants, personal fees and non-financial support from MSD, grants and personal fees from Pfizer, outside the submitted work. TI reports personal fees from Astellas, personal fees from Daiichi-Sankyo, personal fees from Chugai, personal fees from Sanofi, personal fees from AbbVie, personal fees from Bristol-Myers, personal fees from Mitsubishi Tanabe, personal fees from Eisai, personal fees from Janssen, personal fees from Asahi Kasei, personal fees from Ono Pharmaceutical, personal fees from Ayumi Pharmaceutical, personal fees from Pfizer, outside the submitted work. Virginia Steen reports participation in advisory boards, consultancy for economics of scleroderma management, and clinical trials for Bayer; investigator-initiated grant, advisory board, and steering committee (consulting) for CSL Behring; advisory board and site primary investigator (PI) of clinical trial for Roche; site PI of clinical trial for Sanofi; site PI of clinical trial for Immune Tolerance Network; and DSMB for open labs phase 2 trial and site PI for the phase 3 trial for Corbus. ME-T reports consulting fees, speaking fees and honoraria from AbbVie, BMS, Lilly, Medac, MSD, Pfizer, Roche, UCB, outside the submitted work. MW reports employment from Bayer $A G$, outside the submitted work. KL reports other from StatFinn Oy, outside the submitted work. JdOP reports other from Bayer AG, outside the submitted work. ZY reports other from Bayer HealthCare, outside the submitted work. FK reports other from Bayer AG, outside the submitted work.

Patient and public involvement Patients and/or the public were not involved in the design, or conduct, or reporting, or dissemination plans of this research.

Patient consent for publication Not required.

Provenance and peer review Not commissioned; externally peer reviewed.

Data availability statement Availability of the data underlying this publication will be determined according to Bayer's commitment to the European Federation of Pharmaceutical Industries and Associations and Pharmaceutical Research and Manufacturers of America principles for responsible clinical trial data sharing, pertaining to scope, time point and process of data access. Bayer commits to sharing upon request from qualified scientific and medical researchers patient-level clinical trial data, study-level clinical trial data, and protocols from clinical trials in patients for medicines and indications approved in the USA and European Union as necessary for doing legitimate research. This commitment applies to data on new medicines and indications that have been approved by the European Union and US regulatory agencies on or after Jan 1, 2014. Interested researchers can use www.clinicalstud ydatarequest.com to request access to anonymised patient-level data and supporting documents from clinical studies to do further research that can help advance medical science or improve patient care. Information on the Bayer criteria for listing studies and other relevant information is provided in the study sponsors section of the portal. Data access will be granted to anonymised patient-level data, protocols, and clinical study reports after approval by an independent scientific review panel. Bayer is not involved in the decisions made by the independent review panel. Bayer will take all necessary measures to ensure that patient privacy is safeguarded.

Open access This is an open access article distributed in accordance with the Creative Commons Attribution 4.0 Unported (CC BY 4.0) license, which permits others to copy, redistribute, remix, transform and build upon this work for any purpose, provided the original work is properly cited, a link to the licence is given, and indication of whether changes were made. See: https://creativecommons.org/ licenses/by/4.0/.

\section{ORCID iDs}

Dinesh Khanna http://orcid.org/0000-0003-1412-4453 
Christopher P Denton http://orcid.org/0000-0003-3975-8938

Masataka Kuwana http://orcid.org/0000-0001-8352-6136

Janet E Pope http://orcid.org/0000-0003-1479-5302

Sindhu R Johnson http://orcid.org/0000-0003-0591-2976

Richard M Silver http://orcid.org/0000-0002-2038-3278

Oliver Distler http://orcid.org/0000-0002-0546-8310

\section{REFERENCES}

1 Khanna D, Furst DE, Clements PJ, et al. Standardization of the modified Rodnan skin score for use in clinical trials of systemic sclerosis. J Scleroderma Relat Disord 2017;2:11-18.

2 Varga J, Trojanowska M, Kuwana M. Pathogenesis of systemic sclerosis: recent insights of molecular and cellular mechanisms and therapeutic opportunities. I Scleroderma Relat Disord 2017;2:137-52.

3 Denton CP, Khanna D. Systemic sclerosis. Lancet 2017:390:1685-99.

4 Jaeger VK, Wirz EG, Allanore Y, et al. Incidences and risk factors of organ manifestations in the early course of systemic sclerosis: a longitudinal EUSTAR study. PLoS One 2016;11:e0163894.

5 Distler 0 , Highland KB, Gahlemann M, et al. Nintedanib for systemic sclerosisassociated interstitial lung disease. N Engl J Med 2019;380:2518-28.

6 US Food and Drug Administration. FDA approves first treatment for patients with rare type of lung disease. Available: https://www.fda.gov/news-events/pressannouncements/fda-approves-first-treatment-patients-rare-type-lung-disease [Accessed 6 Sep 2019].

7 Sandner P, Stasch JP. Anti-fibrotic effects of soluble guanylate cyclase stimulators and activators: a review of the preclinical evidence. Respir Med 2017;122:S1-9.

8 Matei A-E, Beyer C, Györfi A-H, et al. Protein kinases $G$ are essential downstream mediators of the antifibrotic effects of sGC stimulators. Ann Rheum Dis 2018;77:459.

9 Ghofrani H-A, Galiè N, Grimminger F, et al. Riociguat for the treatment of pulmonary arterial hypertension. N Engl J Med 2013:369:330-40.

10 Huntgeburth M, Kießling J, Weimann G, et al. Riociguat for the treatment of Raynaud's phenomenon: a single-dose, double-blind, randomized, placebo-controlled cross-over pilot study (DIGIT). Clin Drug Investig 2018;38:1061-9.

11 Dees C, Beyer C, Distler A, et al. Stimulators of soluble guanylate cyclase (sGC) inhibit experimental skin fibrosis of different aetiologies. Ann Rheum Dis 2015;74:1621-5.

12 Beyer C, Zenzmaier C, Palumbo-Zerr K, et al. Stimulation of the soluble guanylate cyclase (sGC) inhibits fibrosis by blocking non-canonical TGF $\beta$ signalling. Ann Rheum Dis 2015;74:1408-16.

13 Pan S-L, Guh J-H, Peng C-Y, et al. A potential role of YC-1 on the inhibition of cytokine release in peripheral blood mononuclear leukocytes and endotoxemic mouse models. Thromb Haemost 2005:93:940-8.

14 Ahluwalia A, Foster P, Scotland RS, et al. Antiinflammatory activity of soluble guanylate cyclase: cGMP-dependent down-regulation of P-selectin expression and leukocyte recruitment. Proc Natl Acad Sci U S A 2004;101:1386-91.

15 Beyer C, Reich N, Schindler SC, et al. Stimulation of soluble guanylate cyclase reduces experimental dermal fibrosis. Ann Rheum Dis 2012;71:1019-26.

16 Allanore Y, Distler O. Systemic sclerosis in 2014: advances in cohort enrichment shape future of trial design. Nat Rev Rheumato/ 2015;11:72-4.

17 Maurer B, Graf N, Michel BA, et al. Prediction of worsening of skin fibrosis in patients with diffuse cutaneous systemic sclerosis using the EUSTAR database. Ann Rheum Dis 2015;74:1124-31.

18 Dobrota R, Maurer B, Graf N, et al. Prediction of improvement in skin fibrosis in diffuse cutaneous systemic sclerosis: a EUSTAR analysis. Ann Rheum Dis 2016:75:1743-8.

19 Distler O, Pope J, Denton C, et al. RISE-SSc: riociguat in diffuse cutaneous systemic sclerosis. Respir Med 2017:122:S14-17.

20 van den Hoogen F, Khanna D, Fransen J, et al. 2013 classification criteria for systemic sclerosis: an American College of Rheumatology/European League Against Rheumatism collaborative initiative. Ann Rheum Dis 2013;72:1747-55.
21 LeRoy EC, Medsger TA. Criteria for the classification of early systemic sclerosis. $J$ Rheumatol 2001:28:1573-6.

22 Khanna D, Furst DE, Hays RD, et al. Minimally important difference in diffuse systemic sclerosis: results from the D-penicillamine study. Ann Rheum Dis 2006:65:1325-9.

23 Khanna D, Clements PJ, Volkmann ER, et al. Minimal clinically important differences for the modified Rodnan skin score: results from the scleroderma lung studies (SLSand SLS-II). Arthritis Res Ther 2019;21:23.

24 Khanna D, Berrocal VJ, Giannini EH, et al. The American College of Rheumatology provisional composite response index for clinical trials in early diffuse cutaneous systemic sclerosis. Arthritis Rheumatol 2016:68:299-311.

25 Khanna D, Clements PJ, Furst DE, et al. Recombinant human relaxin in the treatment of systemic sclerosis with diffuse cutaneous involvement: a randomized, double-blind, placebo-controlled trial. Arthritis Rheum 2009;60:1102-11.

26 Khanna D, Merkel PA. Outcome measures in systemic sclerosis: an update on instruments and current research. Curr Rheumatol Rep 2007:9:151-7.

27 Wu W, Jordan S, Graf N, et al. Progressive skin fibrosis is associated with a decline in lung function and worse survival in patients with diffuse cutaneous systemic sclerosis in the European Scleroderma Trials and Research (EUSTAR) cohort. Ann Rheum Dis 2019;78:648-56

28 Amjadi S, Maranian P, Furst DE, et al. Course of the modified Rodnan skin thickness score in systemic sclerosis clinical trials: analysis of three large multicenter, doubleblind, randomized controlled trials. Arthritis Rheum 2009;60:2490-8.

29 Clements PJ, Furst DE, Wong WK, et al. High-dose versus low-dose D-penicillamine in early diffuse systemic sclerosis: analysis of a two-year, double-blind, randomized, controlled clinical trial. Arthritis Rheum 1999;42:1194-203.

30 Postlethwaite AE, Wong WK, Clements $\mathrm{P}$, et al. A multicenter, randomized, doubleblind, placebo-controlled trial of oral type I collagen treatment in patients with diffuse cutaneous systemic sclerosis: I. oral type I collagen does not improve skin in all patients, but may improve skin in late-phase disease. Arthritis Rheum 2008;58:1810-22.

31 Herrick AL, Peytrignet $S$, Lunt $M$, et al. Patterns and predictors of skin score change in early diffuse systemic sclerosis from the European Scleroderma Observational Study. Ann Rheum Dis 2018:77:563-70.

32 Volkmann ER, Tashkin DP, Li N, et al. Mycophenolate mofetil versus placebo for systemic sclerosis-related interstitial lung disease: an analysis of scleroderma lung studies I and II. Arthritis Rheumatol 2017;69:1451-60.

33 Hsu VM, Denton CP, Domsic RT, et al. Pomalidomide in patients with interstitial lung disease due to systemic sclerosis: a phase II, multicenter, randomized, double-blind, placebo-controlled, parallel-group study. J Rheumatol 2018:45:405-10.

34 Ramiro S, Sepriano A, Chatzidionysiou K, et al. Safety of synthetic and biological DMARDs: a systematic literature review informing the 2016 update of the EULAR recommendations for management of rheumatoid arthritis. Ann Rheum Dis 2017:76:1101-36.

35 Prado MS, Bendtzen K, Andrade LEC. Biological anti-TNF drugs: immunogenicity underlying treatment failure and adverse events. Expert Opin Drug Metab Toxicol 2017:13:985-95.

36 Nathan SD, Behr J, Collard HR, et al. Riociguat for idiopathic interstitial pneumoniaassociated pulmonary hypertension (RISE-IPP): a randomised, placebo-controlled phase 2B study. Lancet Respir Med 2019;7:780-90.

37 Khanna D, Spino C, Johnson S, et al. Abatacept in early diffuse cutaneous systemic sclerosis: results of a phase II investigator-initiated, multicenter, double-blind, randomized, placebo-controlled trial. Arthritis Rheumatol 2020;72:125-36.

38 Khanna D, CJF L, Kuwana M. Efficacy and safety of tocilizumab for the treatment of systemic sclerosis: results from a phase 3 randomized controlled trial [abstract] Arthritis Rheumatol 70 (suppl 10), 2018. Available: https://acrabstracts.org/abstract/ efficacy-and-safety-of-tocilizumab-for-the-treatment-of-systemic-sclerosis-resultsfrom-a-phase-3-randomized-controlled-trial/ [Accessed 23 Mar 2020].

39 Denton CP, Merkel PA, Furst DE, et al. Recombinant human anti-transforming growth factor beta1 antibody therapy in systemic sclerosis: a multicenter, randomized, placebo-controlled phase I/II trial of CAT-192. Arthritis Rheum 2007;56:323-33. 